\title{
Fish predation on corals promotes the dispersal of coral symbionts
}

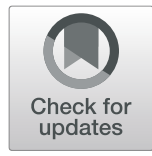

\author{
Carsten G. B. Grupstra ${ }^{*}$ (D), Kristen M. Rabbitt, Lauren I. Howe-Kerr and Adrienne M. S. Correa
}

\begin{abstract}
Background: The microbiomes of foundation (habitat-forming) species such as corals and sponges underpin the biodiversity, productivity, and stability of ecosystems. Consumers shape communities of foundation species through trophic interactions, but the role of consumers in dispersing the microbiomes of such species is rarely examined. For example, stony corals rely on a nutritional symbiosis with single-celled endosymbiotic dinoflagellates (family Symbiodiniaceae) to construct reefs. Most corals acquire Symbiodiniaceae from the environment, but the processes that make Symbiodiniaceae available for uptake are not resolved. Here, we provide the first comprehensive, reefscale demonstration that predation by diverse coral-eating (corallivorous) fish species promotes the dispersal of Symbiodiniaceae, based on symbiont cell densities and community compositions from the feces of four obligate corallivores, three facultative corallivores, two grazer/detritivores as well as samples of reef sediment and water.

Results: Obligate corallivore feces are environmental hotspots of Symbiodiniaceae cells: live symbiont cell concentrations in such feces are 5-7 orders of magnitude higher than sediment and water environmental reservoirs. Symbiodiniaceae community compositions in the feces of obligate corallivores are similar to those in two locally abundant coral genera (Pocillopora and Porites), but differ from Symbiodiniaceae communities in the feces of facultative corallivores and grazer/detritivores as well as sediment and water. Combining our data on live Symbiodiniaceae cell densities in feces with in situ observations of fish, we estimate that some obligate corallivorous fish species release over 100 million Symbiodiniaceae cells per $100 \mathrm{~m}^{2}$ of reef per day. Released corallivore feces came in direct contact with coral colonies in the fore reef zone following $91 \%$ of observed egestion events, providing a potential mechanism for the transfer of live Symbiodiniaceae cells among coral colonies.

Conclusions: Taken together, our findings show that fish predation on corals may support the maintenance of coral cover on reefs in an unexpected way: through the dispersal of beneficial coral symbionts in corallivore feces. Few studies examine the processes that make symbionts available to foundation species, or how environmental reservoirs of such symbionts are replenished. This work sets the stage for parallel studies of consumer-mediated microbiome dispersal and assembly in other sessile, habitat-forming species.
\end{abstract}

Keywords: Butterflyfish, Corallivore, Coral reefs, Dispersal, Feces, Filefish, Microbiome, Predation, Parrotfish, Sediment, Surgeonfish, Symbiodiniaceae, Water column

* Correspondence: Cgg4@rice.edu

BioSciences at Rice, Rice University, 6100 Main St, MS-140, Houston, TX 77005, USA

(c) The Author(s). 2021 Open Access This article is licensed under a Creative Commons Attribution 4.0 International License, which permits use, sharing, adaptation, distribution and reproduction in any medium or format, as long as you give appropriate credit to the original author(s) and the source, provide a link to the Creative Commons licence, and indicate if changes were made. The images or other third party material in this article are included in the article's Creative Commons licence, unless indicated otherwise in a credit line to the material. If material is not included in the article's Creative Commons licence and your intended use is not permitted by statutory regulation or exceeds the permitted use, you will need to obtain permission directly from the copyright holder. To view a copy of this licence, visit http://creativecommons.org/licenses/by/4.0/. 


\section{Introduction}

Most animals and plants studied to date host resident communities of microorganisms - microbiomes-that influence their health and survival [7, 38]. Many hosts establish or modify their microbiome by taking up microorganisms from the environment [41]. Stony corals, for example, harbor single-celled dinoflagellates in the family Symbiodiniaceae and utilize their photosynthetic products to fuel the construction of reef frameworks [44]. Approximately $75 \%$ of spawning and 10\% of brooding coral species acquire their Symbiodiniaceae from the environment with each generation [5], and adult corals may take up environmental Symbiodiniaceae cells to replenish their microbiomes following abiotic stress [8, 34, 58]. However, the dispersal mechanisms that make Symbiodiniaceae cells available to prospective host corals have not been resolved (but see $[15,45]$ ), and Symbiodiniaceae cell densities in environmental reservoirs appear relatively low (sediments: $10^{1}-10^{3}$ cells $\mathrm{ml}^{-1}$; seawater: $10^{0}-10^{1}$ cells $\mathrm{ml}^{-1}$; macroalgae: $10^{2}-10^{3}$ cells $\mathrm{ml}^{-1}$, Fig. 1 [14, 22, 35]).

Consumers (e.g., nectarivores, herbivores, predators) are known to mediate the dispersal of microbiome constituents for various host organisms. Nectar-associated yeasts and bacteria, for example, are transmitted by nectarivores [10], and fungi associated with plant mycorrhiza are dispersed in the feces of diverse herbivorous animals [64]. Corallivores (coral-eating fish and invertebrates) that feed on corals without killing them may similarly mediate the dispersal of coral microbiomes by egesting Symbiodiniaceae-and other members of the coral microbiome-in their feces as they move across reefs [43, 59]. A total of 128 fish species spanning 11 families consume corals as part (i.e., facultative corallivores) or all (i.e., obligate corallivores) of their diets, and most of them occur in the Indo-Pacific or the Red Sea $[16,57]$. To date, dispersal of Symbiodiniaceae has been quantified from one fish species: the Caribbean facultative corallivorous parrotfish Sparisoma viride [14]. Symbiodiniaceae cells were identified in 93\% of fecal samples; cell densities in most samples were similar to those in sediments (although in some samples, cell concentrations were up to 10-fold higher [14, 35]). Molecular approaches detected three Symbiodiniaceae genera from $S$. viride feces, and two of those genera (Symbiodinium and Breviolum) commonly associate with Caribbean soft and stony corals. However, Cladocopium and Durusdinium, the two other genera commonly detected in Caribbean corals, were not observed in $S$. viride feces [14]. These results provide a first indication that facultative corallivores contribute to the dispersal of some coral-associated Symbiodiniaceae genera, at cell concentrations at least comparable to sediments. Obligate corallivores, however, ingest higher abundances of coral tissue than facultative corallivores and may therefore be more important drivers of Symbiodiniaceae dispersal, but this has not been studied. We conducted the first comprehensive, reef-scale quantification of fishmediated coral microbiome dispersal on a Pacific reef and found, surprisingly, that the feces of both obligate and facultative corallivorous fishes contain high densities of live Symbiodiniaceae cells. Thus, this study adds a new dimension to our understanding of the potential outcomes of predation and reveals an important dispersal mechanism for Symbiodiniaceae on Pacific reefs.

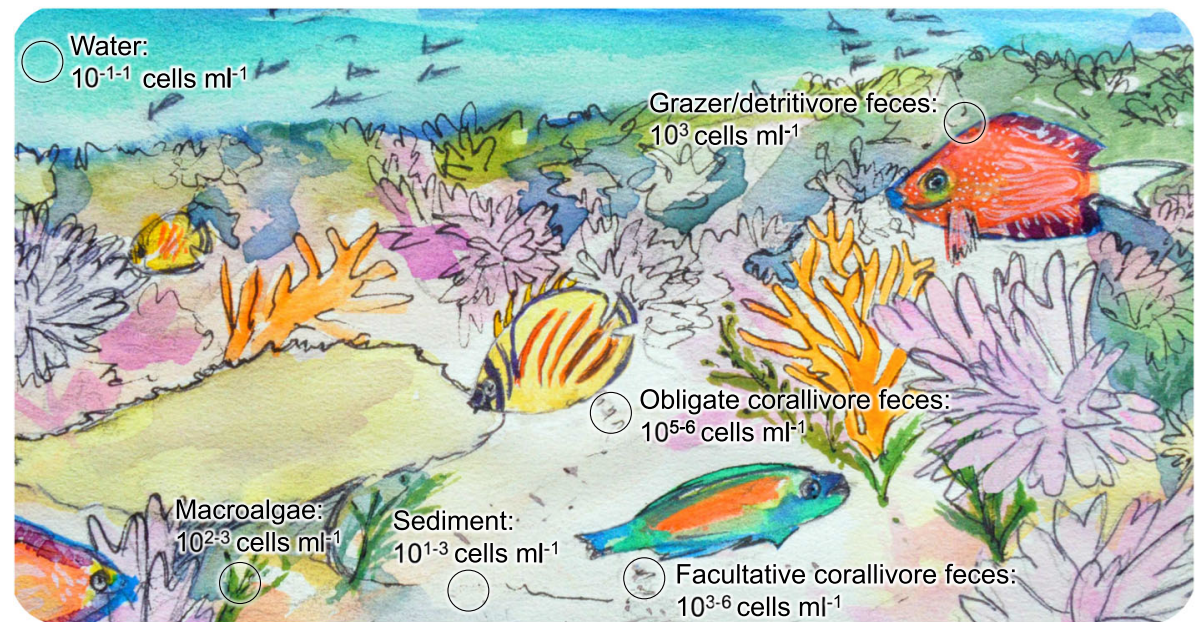

Fig. 1 Summary of the Symbiodiniaceae cell densities quantified from coral reef environmental reservoirs in this and other studies. Cell densities reported in this study (all obligate corallivore and grazer/detritivore feces data and some data for facultative corallivore feces, sediments and seawater) represent live cell densities only, based on results from hemocytometry with the cell viability dye, trypan blue. Previously published cell densities for sediment and seawater [22, 35], macroalgae [22], and facultative corallivore feces [14] may include both dead and live cells and were quantified using hemocytometry [14], a combination of flow-cytometry and hemocytometry [35], or quantitative PCR [22] 
We characterized Symbiodiniaceae densities and community compositions in the feces of four obligate corallivores (the butterflyfishes Chaetodon lunulatus, CHLU; Chaetodon ornatissimus, CHOR; Chaetodon reticulatus, CHRE; and the filefish Amanses scopas, AMSC) and three facultative corallivores (the butterflyfishes Chaetodon citrinellus, CHCI; and Chaetodon pelewensis, CHPE, and the parrotfish Chlorurus spilurus, CHSP) from a reefscape in Mo'orea, French Polynesia [16, 18, 57]. To test whether the feces of obligate corallivores constitute 'hotspots' of live Symbiodiniaceae and are proximate environmental sources of Symbiodiniaceae for prospective coral host colonies, we additionally characterized Symbiodiniaceae from reef-associated sediments and water as well as the feces of two grazer/detritivores (surgeonfishes Ctenochaetus flavicauda, CTFL; and Ctenochaetus striatus, CTST). We then compared Symbiodiniaceae communities in all of these samples to symbionts harbored by locally common reef-building corals Acropora hyacinthus, Pocillopora species complex and Porites lobata species complex [13, 20, 21, 23]. Next, we used bootstrap models based on in situ surveys and observations to generate the first reef-scale predictions of Symbiodiniaceae dispersal for three corallivorous fish species. Finally, we quantified how often egested feces came in direct contact with coral colonies in situ to estimate how frequently fish egestion potentially influences Symbiodiniaceae community assembly in coral hosts.

\section{Results and discussion}

Most corallivorous fish feces contain live Symbiodiniaceae cells

A fecal sample was isolated from the hindgut of each of 76 fishes $(n=6-14$ individuals per species; 9 species; see Table S1 for replication) so that fecal material examined had passed through the entirety of the fish digestive tract. We then measured the volume and mass of each fecal sample and examined it for the presence of live Symbiodiniaceae cells. Sediment and water samples were included as environmental controls $(n=12$ each). We used a Neubauer hemocytometer and a light microscope, and samples were stained with Trypan Blue to identify Symbiodiniaceae cells that were live at the time of preservation (Figure S1 [60, 68]). We detected live Symbiodiniaceae cells in $100 \%$ of obligate corallivore feces $(n=40$, across four species) and in $\sim 82 \%$ of facultative corallivore feces using microscopy $(n=18$ of 22 , across three species). Live Symbiodiniaceae cells were detected by this visual method in $\sim 36 \%$ of grazer/detritivore feces ( $n=5$ of 14 , across two species), $\sim 42 \%$ of sediment samples $(n=5$ of 12$)$ and $\sim 8 \%$ of seawater samples $(n=1$ of 12$)$.
Live Symbiodiniaceae cell concentrations are highest in obligate corallivore feces

Live Symbiodiniaceae cell densities $\mathrm{ml}^{-1}$ differed among species and environmental samples (Fig. 2; Overall Kruskal-Wallis test results: chi-squared $=85.21, \mathrm{df}=10$, $p$-value $<0.001)$, with higher mean live cell densities observed in the feces of each obligate corallivore species than in feces of grazer/detritivore species and sediment and water samples (Fig. 2; Table S2). Dead Symbiodiniaceae cell densities also differed among species and environmental samples, with higher concentrations of dead Symbiodiniaceae cells in corallivore feces than in environmental samples (Fig. 2; Table S2; Overall Kruskal-Wallis test results: chi-squared $=72.36, \mathrm{df}=10, p$-value $<0.001$ ).

Mean live Symbiodiniaceae cell concentrations in individual obligate corallivore species (Fig. 2) ranged from $7.96 \cdot 10^{5} \pm 5.15 \cdot 10^{5}$ (Amanses scopas) to $7.62 \cdot 10^{6} \pm$ $2.55 \cdot 10^{6}$ (Chaetodon reticulatus) $\mathrm{ml}^{-1}$ of feces and were 4-5 orders of magnitude higher than sediment samples $(22.75 \pm 22.37)$ and $6-7$ orders of magnitude higher than seawater samples $(0.23 \pm 0.51)$. Mean live Symbiodiniaceae cell densities in feces of facultative corallivore species were more variable than obligate corallivores and ranged from $2.11 \cdot 10^{4} \pm 2.76 \cdot 10^{4}$ (Chlorurus spilurus) to $2.09 \cdot 10^{6} \pm 1.94 \cdot 10^{6}$ (Chaetodon pelewensis) $\mathrm{ml}^{-1}$ feces. Overall, live Symbiodiniaceae cell densities in corallivore feces in this study were 1-3 orders of magnitude higher than values previously reported from the corallivorous Carribean parrotfish Sparisoma viride (live and dead cells combined: $3.21 \cdot 10^{3}-8.90 \cdot 10^{3}$ cells $\left.\mathrm{ml}^{-1}[14]\right)$. The higher cell densities observed in our study are likely due to dietary differences among fishes. In general, the corallivores in our study rely on corals for a larger part of their diets than S. viride [14, 24], and are therefore expected to ingest higher abundances of Symbiodiniaceae cells. The exception to this is C. spilurus which, like Sparisoma viride, is a facultative corallivore. In our study, C. spilurus bit coral at a lower rate $(\sim 6 \%$, data not shown) than was reported for $S$. viride $(\sim 13 \%$ bite rate, [14]). Despite this, C. spilurus feces still contained Symbiodiniaceae densities an order of magnitude higher than S. viride feces [14]. Methodological differences may explain this apparent discrepancy: Castro-Sanguino and Sánchez [14] collected feces from the benthos after egestion by $S$. viride and sieved the fecal pellets, which likely resulted in the loss of more Symbiodiniaceae cells, compared to direct sampling from fish hindguts (this study).

Symbiodiniaceae cells in corallivore feces are competent for division and long-term survival

The long-term viability of Symbiodiniaceae cells in feces was further confirmed through culturing (attempted from 61 fish fecal pellets using 24 replicate wells per 


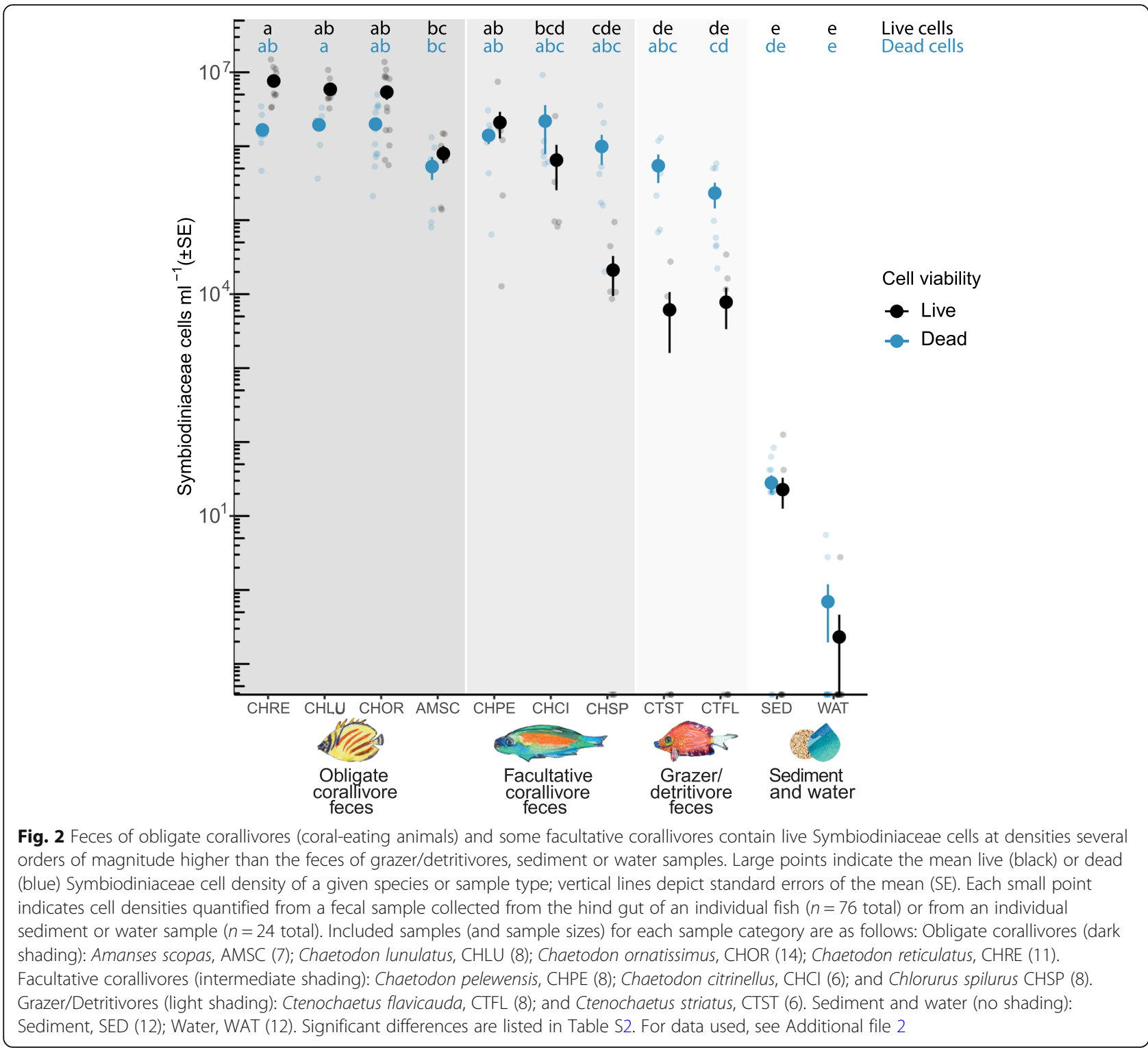

sample; 1464 wells total). Six to 10 weeks after cultures were instigated, live Symbiodiniaceae cells in coccoid, mitotic and motile life stages were documented in at least one replicate culture well from $54 \%$ of obligate corallivore feces $(n=19$ of 35 samples), $11 \%$ of facultative corallivore feces ( $n=2$ of 18 samples), and $38 \%$ of grazer/detritivore feces ( $n=3$ of 8 samples) indicating that the feces of various reef fish consumers contain Symbiodiniaceae cells that are competent for division and long-term survival. Additional research is needed to explore the variation in symbiont culturing success detected across consumer categories, specifically whether corallivore traits and/or variation in Symbiodiniaceae diversity drove the observed differences.
The communities of Symbiodiniaceae in obligate corallivore feces are most similar to those in locally abundant corals

To examine whether Symbiodiniaceae communities in corallivore feces constitute a potential source of symbiont cells for uptake by local corals, we characterized community compositions of Symbiodiniaceae in all our samples (fish feces, sediment and water) as well as in three common coral species (Acropora hyacinthus, Pocillopora species complex, and Porites lobata species complex; $n=12$ per coral species; Table S1) by sequencing the internal transcribed spacer-2 (ITS-2) region of Symbiodiniaceae rDNA. The coral species examined here harbor unique Symbiodiniaceae communities [52, 58 ] and are members of coral genera frequently targeted 
by the corallivores in this study [50]. At the genus level, symbiont communities differed among coral species, obligate corallivore feces, grazer/detritivore feces, and facultative corallivore feces, reef sediments and seawater (PERMANOVA: $\mathrm{df}=6, \mathrm{~F}=17.30, \mathrm{R}^{2}=0.58, p=0.001$; Fig. 3, Figure S2). On average, sequenced reads from obligate corallivore feces were dominated by similarities to Cladocopium (72-98\% of reads), with low relative abundances of reads identified as the genera Durusdinium (2-27\% of reads) and Symbiodinium (0-1\% of reads). Thus, Symbiodiniaceae communities in obligate corallivore feces overall most closely resembled symbiont compositions in the Pocillopora species complex and Porites lobata species complex corals, which mainly harbored symbionts in the genus Cladocopium (Table S3 and S4). This aligns with our observations that the corallivore species in this study rely on pocilloporid and poritid corals for a large part of their diets (observations in this study [50]). It also agrees with the fact that pocilloporid and poritid corals were more common at our study site at the time of sampling, compared to acroporid corals (which were dominated by Durusdinium and Symbiodinium, Fig. 3). Facultative corallivore feces were similar to sediment and seawater samples (Table S3 and S4); these feces contained, on average, less Cladocopium (26-81\%), but more Durusdinium (11-73\%) and Symbiodinium (0$8 \%$ ) than obligate corallivores (Fig. 3). Grazer/detritivore feces were distinct from all other sample categories based on pairwise PERMANOVA test results (Table S4). The Symbiodiniaceae genera Breviolum and Fugacium, which are rare in Mo'orean corals [52], were detected only in grazer/detritivore feces (Fugacium only), reef-associated seawater (Breviolum only) and sediment samples (Fig. 3, S2; Table S3).

\section{Obligate corallivores disperse millions of live Symbiodiniaceae cells per $100 \mathrm{~m}^{2}$ of reef per day}

To generate the first estimates of the daily dispersal of live Symbiodiniaceae cells by corallivorous fish at the reef scale, we applied a bootstrap approach to the product of observed egestion rates, fecal pellet sizes (from in situ field observations), fish densities [9], and live Symbiodiniaceae cell densities and fecal pellet densities (from ex situ measurements) for two obligate corallivores (C. ornatissimus and $C$. reticulatus) and one facultative corallivore (C. citrinellus). This resulted in a probability distribution describing the likely number of live cells dispersed by each species per $100 \mathrm{~m}^{2}$ per day

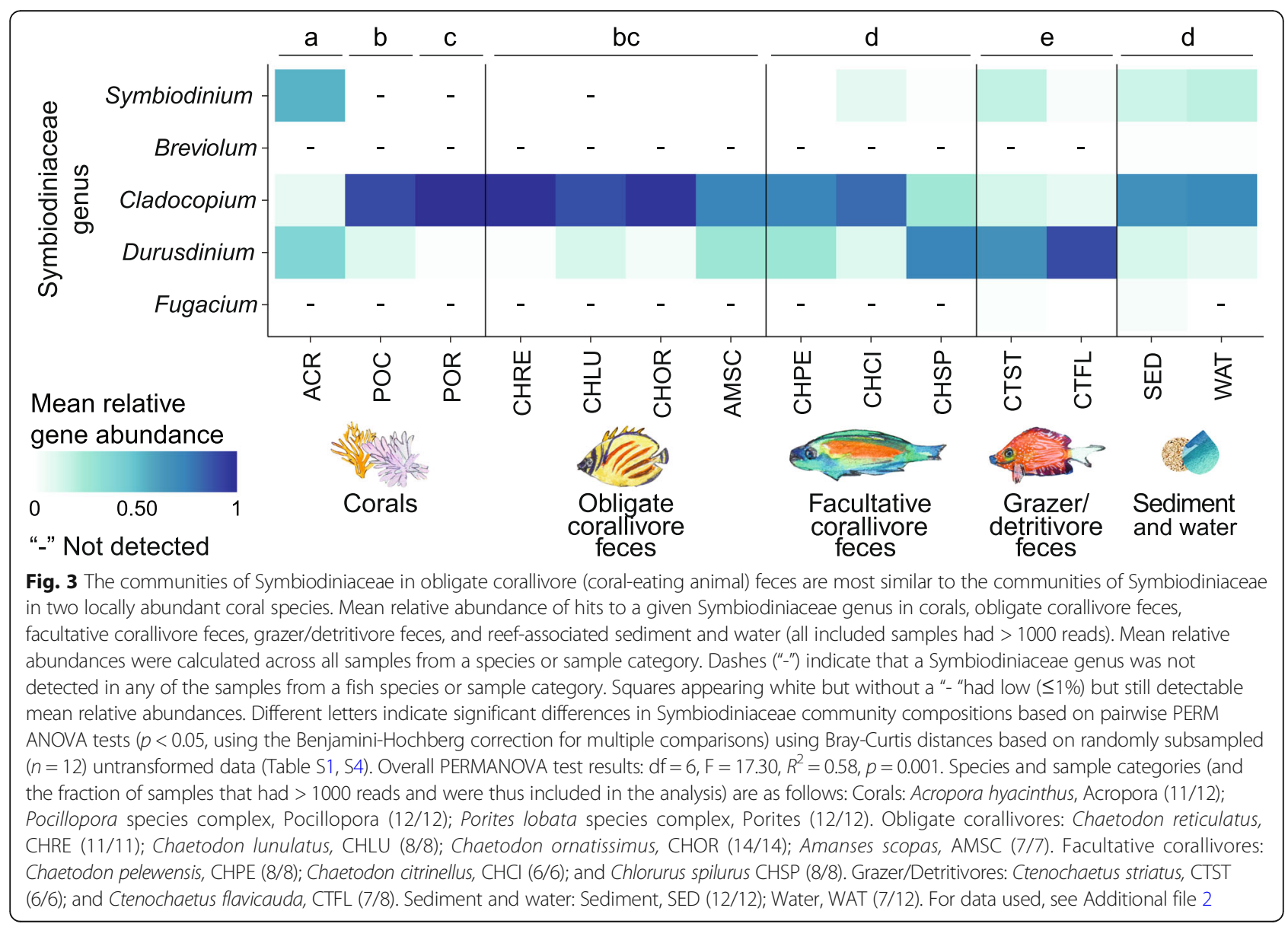




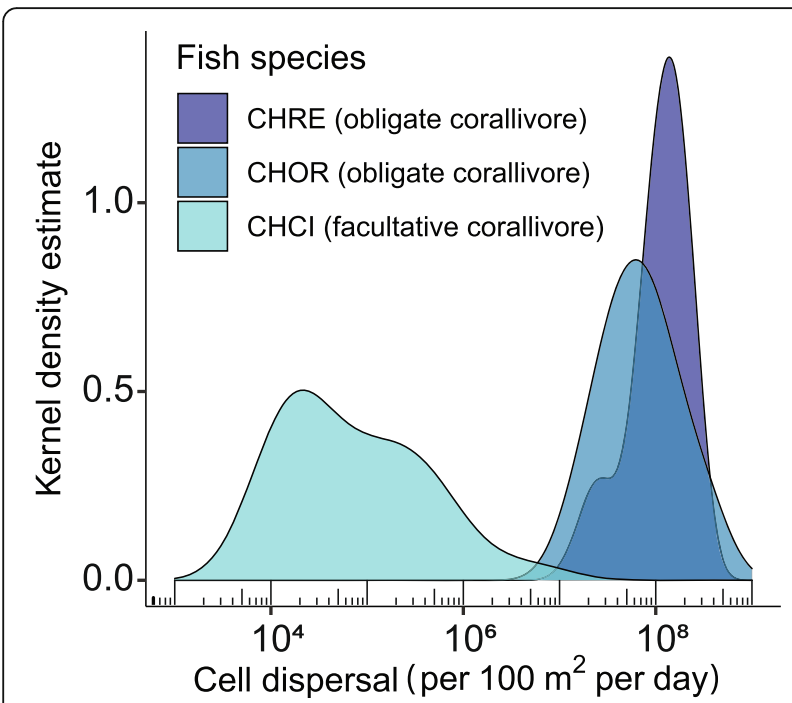

Fig. 4 Corallivores on a South Pacific reef disperse millions of live Symbiodiniaceae cells per $100 \mathrm{~m}^{2}$ per day. We estimated the number of live Symbiodiniaceae cells dispersed by the obligate corallivores Chaetodon ornatissimus (CHOR) and Chaetodon reticulatus (CHRE) and the facultative corallivore Chaetodon citrinellus (CHCl) per $100 \mathrm{~m}^{2}$ per day by applying a bootstrap approach (1000 iterations) to the equation $T=g S W C F$. The estimated number of dispersed Symbiodiniaceae cells $(T)$ is the product of five variables: A fish species-specific constant representing the estimated number of egestions in an eight-hour day (g); observed fecal pellet sizes in $\mathrm{cm}$ $(S)$; measured densities of fecal samples in $\mathrm{g} \mathrm{cm}^{-1}(\mathrm{~W})$; measured densities of Symbiodiniaceae cells $\mathrm{g}^{-1}$ feces (C); and observed fish densities per $100 \mathrm{~m}^{2}$ (F). Due to variation in fish species distributions, most data for CHOR and CHRE were collected on the fore reef, whereas data for $\mathrm{CHCl}$ were collected on the back reef. See Table S5 for replication. For data used see Additional file 2

(Fig. 4). The mean ( $\pm 95 \% \mathrm{CI})$ estimated dispersal rates for the obligate corallivores were $1.01 \cdot 10^{8} \pm 6.50 \cdot 10^{6}$ and $1.27 \cdot 10^{8} \pm 4.61 \cdot 10^{6}$ cells per $100 \mathrm{~m}^{2} \mathrm{~d}^{-1}$, respectively; these were three orders of magnitude higher than the estimated mean for the facultative corallivore $\left(3.32 \cdot 10^{5} \pm\right.$ $\left.6.21 \cdot 10^{4}\right)$. Differences between obligate versus facultative corallivore estimates were mainly driven by higher densities of $C$. ornatissimus and $C$. reticulatus individuals at our study site (4.7-8.8 times higher than C. citrinellus, Table S5), and higher Symbiodiniaceae densities in their feces (3.7-7.5 times higher than C. citrinellus, Table S5, Fig. 2). Further, mean fecal pellet size, fecal density and egestion rates were also 1.1-4.5 times higher for the two obligate corallivores, relative to the facultative corallivore (Table S5).

\section{Corallivores promote the dispersal of live} Symbiodiniaceae cells among coral colonies

Our findings indicate that obligate corallivore feces contain live Symbiodiniaceae cells at densities two to seven orders of magnitude higher than other environmental reservoirs, such as the water column, sediments and macroalgae (this work [22, 35]), and up to three orders of magnitude higher than feces of the one other corallivorous fish that has been examined: the Caribbean parrotfish S. viride [14]. Corallivore feces that come in direct contact with live coral colonies are likely to facilitate the transmission of Symbiodiniaceae cells between colonies. We therefore conducted surveys to estimate the relative frequency at which corallivore feces fell onto such colonies. We observed that egested feces often fell apart into several segments as they fell through the water column, and segments of $\sim 91 \%$ of egested feces landed on live corals at our fore reef site ( $n=20$ of 22 feces). Segments of only $10 \%$ of feces fell onto live corals at our back reef site $(n=3$ of 30 feces), which is consistent with lower mean $( \pm$ SD) live coral cover in this reef zone $(44.80 \% \pm 10.83$ coral cover on the fore reef; $15.33 \% \pm 7.10$ back reef, ANOVA, $\mathrm{df}=1, \mathrm{~F}=44.91, p<0.001)$. These results indicate that fish predators of corals commonly mediate the dispersal of Symbiodiniaceae cells to prospective coral host colonies on Pacific reefs, especially in areas with relatively high coral cover. Additional work is needed to: (1) understand differences in fecal pellet integrity among corallivore species and individuals following egestion; and (2) resolve how subsequent biotic interactions and hydrodynamic conditions influence the duration of fecal contact with potential hosts. This information will support a more nuanced understanding of fecal fates following egestion by corallivorous fish and the associated potential for symbiont cell dispersal and uptake.

\section{Corallivore feces constitute environmental hotspots of live Symbiodiniaceae}

Our findings suggest that the feces of obligate corallivores and at least some facultative corallivores constitute significant but underexplored environmental 'hotspots' of Symbiodiniaceae on coral reefs; such feces may supply Symbiodiniaceae cells to potential hosts directly, or to other environmental reservoirs as they disintegrate [14, 45]. Corals have been shown to take up Symbiodiniaceae from sediments and seawater, as well as from the feces of giant clams [15, 34, 45, 63]. The sea anemone Aiptasia pulchella has also previously been shown to incorporate Symbiodiniaceae from fish feces as symbionts [43]. Thus, although further experimental verification is needed, corals (in at least some life stages and health states) are likely capable of incorporating Symbiodiniaceae from fish feces.

We posit that corallivore feces may be particularly beneficial for juvenile corals (individuals up to 4 years post-settlement), and especially horizontal transmitters, since each generation must assemble its Symbiodiniaceae community from environment pools. Juveniles of diverse coral species are known to readily take up diverse Symbiodiniaceae species from the water column 
and sediments [1-3, 39, 45, 49]. Further, experiments have demonstrated that inoculations of coral juveniles with some Symbiodiniaceae species may increase postsettlement survival and growth [40, 61]. Experiments examining how contact with the feces of different fish consumer groups influences the health and survival of coral juveniles, the time to establishment and composition of their Symbiodiniaceae communities, as well as other factors (e.g., colony growth rate) constitute important next steps in exploring the ecological implications of consumer-mediated symbiont dispersal on reefs and analogous systems. The impact of feces from different fish consumer groups on coral colony health and Symbiodiniaceae community assembly in adult corals should also be tested experimentally. Limited evidence suggests that adult coral colonies may take up novel Symbiodiniaceae species during or following environmental stress $[8,34,58]$, but the influence of predator feces has not been examined. A tractable first step is to test whether adult coral colonies that have lost most or all of their symbionts (i.e. bleached, [66]) recover their Symbiodiniaceae communities more quickly-or exhibit higher survival-when exposed to corallivore feces. Finally, these lines of inquiry can be extended to other members of the coral microbiome, such as bacteria, which also contribute to the health and disease of their hosts $[54,56]$.

The dispersal of beneficial microorganisms may become increasingly important $[19,53]$ as anthropogenic stressors disrupt animal and plant microbiomes, leading to disease and mortality [28, 31, 48, 67]. Our results suggest that shifts and declines in fish communities due to overfishing [6, 26, 37] and habitat degradation [51, 65] may contribute to an unexplored issue on reefs: altered (or reduced) dispersal of Symbiodiniaceae, a key member of the coral microbiome. Coral-Symbiodiniaceae partnerships have been increasingly disrupted over the past four decades, resulting in coral reef decline [28, 67]. To help corals tolerate stress and mitigate reef degradation [47], probiotic solutions of beneficial Symbiodiniaceae [42] and bacteria [55] are currently being developed. We show that corallivores egest feces containing high densities of live Symbiodiniaceae cells directly onto corals. This behavior may constitute a routine, globalscale 'restoration effort' that inoculates corals with natural probiotics derived from nearby colonies. It is thus important that healthy fish assemblages are maintained on reefs as the potentially stabilizing effect of corallivores on coral microbiomes is investigated.

\section{Conclusion}

Climate change stressors, along with overfishing and nutrient pollution, are driving the loss of coral reefs globally. The roles of herbivores in maintaining a coral- dominated reef state, particularly following disturbance, are well established (e.g. [11, 12]). Our findings suggest that corallivorous fish may also contribute to the success and resilience of corals, because their feces constitute environmental hotspots of Symbiodiniaceae from which corals may acquire (or replenish) their microbiomes. The approaches used here can be broadly applied to studying the dispersal of symbiotic microorganisms via trophic interactions and set the stage for parallel studies of consumer-mediated microbiome dispersal and assembly in other sessile, habitat forming species.

\section{Methods}

Individuals of nine fish species, as well as corals, sediments, and seawater samples $(n=6-14$ per sample type or species, see Table S1) were collected on scuba in July and August 2019 from two reef zones: the back reef (1-2 m depth) and fore reef (5-10 m depth), between LTER sites 1 and 2 of the Mo'orea Coral Reef (MCR) Long Term Ecological Research (LTER) site. We selected fish species that broadly differ in their level of corallivory based on published literature $[18,24,57,65]$ as obligate corallivores (butterflyfishes Chaetodon lunulatus, Chaetodon ornatissimus, Chaetodon reticulatus, and the filefish Amanses scopas), facultative corallivores (butterflyfishes Chaetodon citrinellus and Chaetodon pelewensis and the parrotfish Chlorurus spilurus) and grazer/detritivores (surgeonfishes Ctenochaetus flavicauda and Ctenochaetus striatus). We sampled three coral species (Acropora hyacinthus, Pocillopora species complex [23], and Porites lobata species complex $[20,21])$ that are dominant reef builders in Mo'orea and that are members of genera frequently targeted by corallivores [13, 50]. These coral species harbor unique Symbiodiniaceae communities [52, 58].

\section{Sample processing}

Following collection, all fish were euthanized and immediately transported on ice to the lab for Symbiodiniaceae density, viability, and community composition analyses. For each collected fish, an incision was made from the pelvic fin to the anus using a sterile scalpel, and the entire digestive tract was removed. Feces were subsequently sampled from the hindgut of each fish individual ( $n=6-14$ per species) so that Symbiodiniaceae condition (live versus dead) was assessed from cells that had passed through the entire fish digestive tract. Characteristics of fecal material were also measured to support reef-scale estimates of Symbiodiniaceae cell dispersal. Fecal samples for Symbiodiniaceae cell counts were preserved in $750 \mu \mathrm{l} 10 \%$ formalin in $100 \mathrm{kDa}$-filtered seawater and weighed using a microbalance immediately after dissection out of each fish (sample weights: range $=$ 22 to $170 \mathrm{mg} ; \mu=73 \mathrm{mg}, \sigma=32$ ). Samples for DNA extractions were preserved in DNA/RNA shield (Zymo 
Research, CA). To calculate fecal densities for reef scale dispersal estimates, another fecal sub-sample was weighed and its length measured.

Six colonies of each coral species were sampled from the tips of their branches (Acropora hyacinthus and Pocillopora species complex) or from the center of the colony (Porites lobata species complex) at both the fore reef and back reef site using bone cutters. All coral samples were taken from colonies that were at least $5 \mathrm{~m}$ apart. Each coral fragment was preserved for DNA extractions in DNA/RNA shield (Zymo Research, CA); samples for Symbiodiniaceae cell density analyses were not collected from corals.

Sediment and seawater samples were collected and processed using a protocol modified from Littman et al. [35]. Seawater samples (3.81 each) were collected from the fore reef and back reef ( $n=6$ per reef zone) at a distance of $10-100 \mathrm{~cm}$ off the reef bottom (at least $10 \mathrm{~m}$ apart). The samples were concentrated to $\sim 100 \mathrm{ml}$ using tangential flow filtration $(0.2 \mu \mathrm{m})$, divided into two $50 \mathrm{ml}$ subsamples and filtered onto two separate $0.45-\mu \mathrm{m}$ filters using a vacuum pump. One filter per sample was preserved for Symbiodiniaceae cell counts by resuspension in $3 \mathrm{ml} \mathrm{5 \%}$ formalin in $100 \mathrm{kDa}$-filtered seawater and vortexing at maximum speed for $10 \mathrm{~min}$. The other filter was preserved for the isolation of genomic material in $6 \mathrm{ml}$ of DNA/RNA shield (Zymo Research, CA) with $1.35 \mathrm{~g}$ Lysing Matrix A garnet and 5 0.6- $\mathrm{cm}$ ceramic beads (MPBio, California) and vortexed for $20 \mathrm{~min}$.

Pooled reef sediment samples (totaling $500 \mathrm{ml}$ each) were collected concomitantly with water column samples ( $n=6$ per reef zone). Samples were pooled from ten sterile $50 \mathrm{ml}$ conical tubes filled at five random locations in a $10 \mathrm{~m}$ radius from where the associated seawater sample was collected. To best approximate the Symbiodiniaceae cells that would be available for uptake by nearby coral colonies, sediment collections were focused at the sediment-water interface (no deeper than $5 \mathrm{~cm}$ ) and occurred less than $1 \mathrm{~m}$ from live coral colonies. Sediments were immediately washed over a $120-\mu \mathrm{m}$ nylon mesh using $500 \mathrm{ml} 100 \mathrm{KDa}$ filtered seawater and filtered through a $20-\mu \mathrm{m}$ nylon mesh. The flow-through was then processed in the same manner as described above for seawater samples.

\section{Symbiodiniaceae cell density and viability}

All cell count samples were homogenized using a Fisher Scientific homogenizer F150 for $5 \mathrm{~s}$ (to break up cell clumps) and subsequently filtered through 120 and $20 \mu \mathrm{m}$ nylon filters to reduce the density of debris in samples. The volume of each fecal sample was measured using a $1 \mathrm{ml}$ pipettor (range $=42$ to $234 \mu \mathrm{l}, \mu=109 \mu \mathrm{l}$, $\sigma=45)$. Symbiodiniaceae cells in fish feces, seawater and sediments were manually quantified (the mean of eight technical replicates) using light microscopy (20X) with a Neubauer hemocytometer. During counts, cells were counted as Symbiodiniaceae if they were of the correct size (6-12 $\mu \mathrm{m}$ [32]), had visible organelles, a coccoid shape, and a large pyrenoid accumulation body [35, 45]. Subsamples were frequently viewed at higher magnification to verify their identity, using cultured Symbiodiniaceae cells (live and dead) as visual references. Cell densities were expressed as cells per $\mathrm{ml}$ source material (feces, water, sediment) by dividing the cell concentration by the fraction of sample in the summed volume of fixative, stain and sample volume, and multiplying this by 1000 . All samples were stained with $0.16 \%$ trypan blue $5 \mathrm{~min}$ before processing to parse live from dead cells $[25,60,68]$. Individual cells were interpreted as having been 'live' at the time of fixation if, following staining, they retained a golden-brown color (see figure S1 in the Supplementary Materials). Cells were interpreted as 'dead' at the time of fixation if staining turned them blue. We did not detect live Symbiodiniaceae cells in some C. spilurus feces, some grazer/detritivore feces and in some sediment and water samples. To avoid overinflating live Symbiodiniaceae cell density averages for these sample types, we entered cell concentrations of 0 cells $\mathrm{ml}^{-1}$ for these samples, rather than excluding samples below the detection limit.

We utilized cell culturing to confirm that Symbiodiniaceae cells in fish feces could remain viable for an extended period following passage through a consumer digestive tract culturing (fecal pellets from $n=61$ individual fish, 24 replicate wells per sample; 1464 wells total; Table S1). Briefly, subsamples of fecal pellets were suspended in $1 \mathrm{ml}$ of $100 \mathrm{KDa}$-filtered seawater in a sterile petri dish. Then, $20 \mathrm{ul}$ of this suspension was pipetted into each of 24 replicate wells in a 96-well plate filled with 200 ul sterile F/2 media. The culture plates were stored at room temperature under fluorescent lighting on a 12:12 light:dark cycle for up to 6 weeks and then transported back to Rice University (Houston, TX, USA), where they were transferred to an incubator set to $25^{\circ} \mathrm{C}$ on a 12:12 light:dark cycle. All culture wells were examined after 6-10 weeks using a compound microscope with 20x and 40x magnification and scored for the presence/absence of intact Symbiodiniaceae cells.

\section{Symbiodiniaceae community composition}

DNA was extracted using the ZymoBIOMICs DNA/ RNA Miniprep kit (Zymo Research, CA), and the internal transcribed spacer-2 (ITS-2) region of Symbiodiniaceae rDNA was sequenced following Howe-Kerr et al. [27] using the primers SYM_VAR_5.8SII (5' GAATTG CAGAACTCCGTGAACC $3^{\prime}$ ) and SYM_VAR_REV (5' CGGGTTCWCTTGTYTGACTTCATGC 3') [30] and sequenced on the Illumina MiSeq platform at the 
Georgia Genomics and Bioinformatics Core (University of Georgia, Athens, GA) following details outlined in Howe-Kerr et al. [27]. The resulting sequencing data were processed using Symportal [29]. Samples with $<1000$ reads were discarded and sequencing depth was assessed using rarefaction curves. To circumvent issues related to the interpretation of inter- versus intragenomic variation in the Symbiodiniaceae ITS-2 region [17, 33], ITS2profiles were reduced to number of reads per Symbiodiniaceae genus and expressed as percentages.

\section{Reef-scale Symbiodiniaceae dispersal estimates}

To generate the first estimates of daily dispersal of live Symbiodiniaceae cells by corallivorous fish at the reef scale, we estimated the number of Symbiodiniaceae cells dispersed by the obligate corallivores C. ornatissimus and $C$. reticulatus and the facultative corallivore $C$. citrinellus per $100 \mathrm{~m}^{2}$ per day by applying a bootstrap approach (1000 iterations) to the equation $T=g S W C F$. Here, the estimated number of dispersed Symbiodiniaceae cells $(T)$ is the product of five variables: A speciesspecific constant representing the estimated number of egestions in an eight-hour day $(g)$; fecal pellet sizes in $\mathrm{cm}$ $(S)$; densities of fecal samples in $\mathrm{g} \mathrm{cm}^{-1}(W)$; densities of Symbiodiniaceae cells $\mathrm{g}^{-1}$ feces $(C)$; and fish densities $100 \mathrm{~m}^{-2}(F)$.

We collected data on fish egestion rates $(g)$ and fecal pellet sizes $(S)$ in situ via fish follows in the field between 09:00 $\mathrm{h}$ and 17:00 h (Table S6). Individuals of C. ornatissimus $(n=53), C$. reticulatus $(n=39)$ and C. citrinellus $(n=31)$, were each followed for a mean of 7.9 min $(16.2$ $\mathrm{h}$ of observations total) and all egestion events were recorded. Estimated egestion rates per hour were calculated as the total number of observed egestions divided by the total period of observations per species. We conservatively assumed that the observed fish species were active for $8 \mathrm{~h}$ per day, equal to the time frame over which we made our observations, and that egestion rates remained constant throughout the day. We measured the length of any fecal pellet that fell on a flat surface and remained intact ( $n=12$ total) using a standard ruler. To convert the lengths of fecal pellets to weights $(W)$, we used a precision balance to weigh pre-measured fecal samples from collected individuals of C. citrinellus $(n=4)$, C. ornatissimus $(n=3)$ and $C$. reticulatus $(n=3)$. Cell densities $(C)$ calculated as described above were expressed as live cells $\mathrm{g}^{-1}$ feces.

Fish densities $(F)$ were extracted from the MCR LTER dataset (http://mcrlter.msi.ucsb.edu/cgi-bin/ showDataset.cgi?docid=knb-lter-mcr.6 accessed February 14, 2020). We used fish densities from the fore reef for Chaetodon ornatissimus and Chaetodon reticulatus and data from back reef sites for Chaetodon citrinellus, because the latter species does not occur on the fore reef.
Data from 2019 were not available as of April 2020, so we therefore used data from 2018. Briefly, the MCR LTER collects these data by counting fishes in four replicate $5 \times 50 \mathrm{~m}$ fish belt transects at the two north-shore LTER sites (LTER 1 and 2), resulting in densities of fish $250 \mathrm{~m}^{-2}$ [9]. In this study, we multiplied the LTER data by 0.4 to convert densities to $100 \mathrm{~m}^{-2}$.

\section{Coral cover transects}

Replicate line transects were conducted at our fore reef $(n=5)$ and back reef sites $(n=12)$ to determine live coral cover. Briefly, a $50 \mathrm{~m}$ transect was rolled out parallel to the shoreline and digital images were taken using an Olympus Tough TG6 camera to categorize substrates as "live coral" or "other" at each meter mark. These categorizations were used to calculate average percentages of live coral cover.

\section{Statistical analyses}

For all tests, biological replicates were defined as samples collected from distinct fish individuals; or samples from coral colonies separated by at least $5 \mathrm{~m}$; or sediment or water samples collected at least $10 \mathrm{~m}$ apart. Technical replicates (e.g., in Symbiodiniaceae cell counts) were defined as analyses conducted on multiple sub-samples of an individual biological replicate and not included in the statistical analysis.

We tested for differences in live and dead Symbiodiniaceae cell densities among individual fish species, coral species, and sediment and seawater samples. Briefly, we used Kruskal-Wallis tests and Dunn tests with Bonferronicorrected $p$-values for multiple comparisons (Tables S2\&S3) using dunn.test package v1.3.5. in $\mathrm{R}$ version 3.6.1 [62] because nested linear models violated the model assumptions, even after transformation. However, nested linear models produced the same general results (not shown). We checked for outliers using boxplots and observed one outlier among the facultative corallivore fecal samples. However, this datapoint was in the same range as data for obligate corallivores and was therefore retained.

We used a PERMANOVA in Vegan 2.5-6 [46] to test for differences in genus-level Symbiodiniaceae community compositions among obligate corallivores, facultative corallivores, grazer/detritivores, individual coral species, and sediments and seawater. We found significant heterogeneous dispersion between sample categories using betadisper(). Because PERMANOVA is sensitive to heterogeneous dispersion in concert with an unbalanced design [4], we randomly subsampled 12 rows for each of the four sample categories (All coral samples; Obligate corallivores: 19AMSC4, 19AMSC6, 19AMSC7, 19CHLU2, 19CHLU6, 19CHOR5, 19CHOR7, 19CHOR8, 19CHOR12, 19CHOR14, 19CHRE9, 19CHRE11; facultative corallivores: 19CHCI2, 19CHCI3, 19CHCI4, 19CHPE1, 19CHPE3, 19CHPE4, 19CHPE5, 19CHPE6, 
19CHPE8, 19CHSP2, 19CHSP4, 19CHSP7; Grazer/detritivores: 19CTFL1, 19CTFL3, 19CTFL4, 19CTFL5, 19CTFL6, 19CTFL7, 19CTFL8, 19CTST1, 19CTST3, 19CTST4, 19CTST5, 19CTST6; sediment and water: BAKSED1, BAKSED2, BAKSED4, BAKSED5, FORSED1, FORSED2, FORSED3, FORSED4, FORSED6, FORH2O2, BAKH2O5, FORH2O5). We then tested for differences between sample categories using PERMANOVA with adonis() based on untransformed Bray-Curtis distances. Pairwise tests were conducted with a Benjamini-Hochberg error correction using pairwiseAdonis 0.4 [36].

To test for differences in live coral cover between the back reef and fore reef zones, we used an analysis of variance (ANOVA). We tested for normality of the distributions and of the residuals using a Shapiro test. The assumption of homogeneity of variance was tested using Levene's test.

\section{Abbreviations \\ ANOVA: Analysis of variance; Cl: Confidence interval; ITS-2: Internal transcribed spacer-2; LTER: Long-term Ecological Research; MCR: Mo'orea Coral Reef; PERMANOVA: Permutational multivariate analysis of variance; SD: Standard deviation; SE: Standard error of the mean}

\section{Species and sample types}

ACR: Acropora hyacinthus (stony coral); POC: Pocillopora species complex (stony coral); POR: Porites lobata species complex (stony coral);

AMSC: Amanses scopas (obligate corallivorous filefish); $\mathrm{CHCl}$ : Chaetodon citrinellus (facultative corallivorous butterflyfish); CHLU: Chaetodon lunulatus (obligate corallivorous butterflyfish); CHOR: Chaetodon ornatissimus (obligate corallivorous butterflyfish); CHPE: Chaetodon pelewensis (facultative corallivorous butterflyfish); CHRE: Chaetodon reticulatus (obligate corallivorous butterflyfish); CHSP: Chlorurus spilurus (facultative corallivorous parrotfish); CTFL: Ctenochaetus flavicauda (grazer/detritivore surgeonfish); CTST: Ctenochaetus striatus (grazer/detritivore surgeonfish); SED: Sediment; WAT: Water

\section{Supplementary Information}

The online version contains supplementary material available at https://doi. org/10.1186/s42523-021-00086-4.

Additional file 1: Table S1. Summary of the samples collected and processed in this study for Symbiodiniaceae cell density and viability (Fig. 2), culturing, and community composition based on the internal transcribed spacer-2 (ITS-2) region of rDNA (Fig. 3). Figure S1. Hemocytometry with trypan blue stain accurately differentiates live and dead Symbiodiniaceae cells that were fixed in 10\% formalin. Table S2. Results of pairwise Dunn tests on Symbiodiniaceae cell densities between species, sediment and water samples (Fig. 2). Table S3. Mean relative abundances of genes associated with five Symbiodiniaceae genera identified in this study per sample type (e.g., Amanses scopas feces) and overall sample category (e.g., obligate corallivores) (Fig. 3). Table S4. Results from pairwise PERMANOVA tests on Symbiodiniaceae community composition at the genus level, based on BrayCurtis distances (Fig. 3). Figure S2. The communities of Symbiodiniaceae in obligate corallivore (coral-eating animal) feces are most similar to the communities of Symbiodiniaceae in two locally abundant coral species. Table S5. Overview of values used in bootstrap estimate of reef-scale Symbiodiniaceae dispersal (Fig. 4).

Additional file 2: Source data. The tabs "cell counts_metadata" and "Cellcounts" contain densities of live (unstained by trypan blue; column 'Live') and dead (stained by trypan blue; column 'Dead') Symbiodiniaceae cells $\mathrm{ml}^{-1}$ material (feces, sediment seawater), as determined through cell counts using a hemocytometer and compound microscope at 20x magnification. Reported cell densities are averages of 8 replicate counts. The code to replicate this analysis can be found on https://github.com/ CorreaLab/Fishces_2020/blob/master/Symbiodiniaceae\%20cell\%2 0counts\%20code. The tabs starting with "ITS2" contain sequencing data after processing in Symportal [29]. Individual ITS-2 profiles have been removed to facilitate analysis of Symbiodiniaceae communities at the genus level. All tabs except the "ITS2 metadata" tab are required for analysis using code deposited on https://github.com/CorreaLab/Fishces_202 0/blob/master/Symbiodiniaceae\%20community\%20analysis\%20code. The tab "ITS2 random subsampling" contains the randomly subsampled data used for statistical analysis with PERMANOVA. The tabs "Bootstrap datafile_metadata" and "Bootstrap_datafile" contain the dataset used to estimate the daily dispersal of Symbiodiniaceae cells by three fish species. The column 'Live_g_sample' contains Symbiodiniaceae cell densities $\mathrm{g}^{-}$ fecal sample; the column 'Wet weight' contains the weight of fecal pellets $\mathrm{cm}^{-1}$; the columns 'MCR_LTER_Site' - 'Fish_density' contain fish abundances at four transects of MCR LTER sites 1 and 2; the column 'Pellet_length' contains lengths of fecal pellets as measured during observations in the field. The code to replicate this analysis is available on https://github.com/CorreaLab/Fishces_2020/blob/master/ Symbiodiniaceae\%20cell\%20dispersal\%20bootstrap\%20code

\section{Acknowledgements}

Special thanks go to Deron Burkepile and Erika Eliason for input on the study design and providing some materials used to conduct this work. For support in the field, the authors express their sincere appreciation to Jake Emmert and Ryan Hannum from the Aquarium at Moody Gardens, Inc. (Galveston, Texas), and to Journ Galvan, Haley Glasman, Maya Gorgas, Ashtyn Isaak, Kai Kopecky, Kaitlyn Landfield, Hunter Lenihan, Jacey van Wert and Erin Winslow. Further thanks go to Tom E.X. Miller, Dave W. Armitage and Daniel J. Gorczynski for input on the data analysis. Many thanks to Janavi Mahimtura Folmsbee for designing and creating a painting for Fig. 1, and Thiago B.S. Correa for a suggestion that improved Fig. 1. Lastly, we would like to thank two anonymous reviewers for feedback that significantly improved the manuscript.

\section{Authors' contributions}

C.G. and A.C. conceived of the experiments; C.G. and K.R. developed the methods with support from A.C.; C.G., L.I.H. and K.R. conducted the experiments; C.G. led data analysis, with contributions by all authors; C.G. wrote the first draft of the manuscript, with contributions by all authors. All authors read and approved the final manuscript.

\section{Funding}

This study was made possible by support from the Wagoner Foreign Study Scholarship Program to C.G. and K.R., the Lewis and Clark Fund for Exploration to C.G., the Garden Club of America Clara Carter Higgins Fund and the Explorer's Club Youth Activity Fund to K. R, a U.S. National Science Foundation award (OCE \#1635798) to A.M.S.C., and an Early-Career Research Fellowship (\#2000009651) from the Gulf Research Program of the National Academies of Sciences to A.M.S.C.

\section{Availability of data and materials}

Cell counts data have been uploaded to Dryad (doi:https://doi.org/10.5061/ dryad.80gb5mkpd). Raw amplicon sequencing data have been deposited on NCBI's SRA (sequence read archive; accession PRJNA655793). Source data files have been provided for figures 2-4 in "Additional file 2". All code used for analyses is available on Github https://github.com/CorreaLab/Fishces_2020.

\section{Declarations}

Ethics approval and consent to participate

Research was completed under permits issued by the French Polynesian Government (Délégation à la Recherche) and the Haut-commissariat de la République en Polynésie Francaise (DTRT) (Protocole d'Accueil 2005-2020). This work represents a contribution of the Moorea Coral Reef (MCR) LTER Site (NSF OCE 1637396). All samples were collected under approval of the institutional animal care and use committee (IACUC) at Rice University [IRBNet ID 1429151-4].

Consent for publication

Not applicable. 


\section{Competing interests}

The authors declare no competing interests.

\section{Received: 16 October 2020 Accepted: 5 March 2021} Published online: 22 March 2021

\section{References}

1. Abrego D, Van Oppen MJH, Willis BL. Onset of algal endosymbiont specificity varies among closely related species of Acropora corals during early ontogeny. Mol Ecol. 2009;18(16):3532-43. https://doi.org/10.1111/j.13 65-294X.2009.04276.X.

2. Adams LM, Cumbo VR, Takabayashi M. Exposure to sediment enhances primary acquisition of Symbiodinium by asymbiotic coral larvae. Mar Ecol Prog Ser. 2009;377:149-56. https://doi.org/10.3354/meps07834.

3. Ali A, Kriefall NG, Emery LE, Kenkel CD, Matz MV, Davies SW. Recruit symbiosis establishment and Symbiodiniaceae composition influenced by adult corals and reef sediment. Coral Reefs. 2019;38(3):405-15. https://doi. org/10.1007/s00338-019-01790-z.

4. Anderson MJ, Walsh DCI. PERMANOVA, ANOSIM, and the mantel test in the face of heterogeneous dispersions: what null hypothesis are you testing? Ecol Monogr. 2013;83(4):557-74. https://doi.org/10.1890/12-2010.1.

5. Baird AH, Guest JR, Willis BL. Systematic and biogeographical patterns in the reproductive biology of Scleractinian corals. Annu Rev Ecol Evol Syst. 2009; 40:551-71. https://doi.org/10.1146/annurev.ecolsys.110308.120220.

6. Bellwood DR, Choat JH. Dangerous demographics: the lack of juvenile humphead parrotfishes Bolbometopon muricatum on the great barrier reef. Coral Reefs. 2011;30(2):549-54. https://doi.org/10.1007/s00338-011-0738-2.

7. Bosch TCG, McFall-Ngai MJ. Metaorganisms as the new frontier. Zoology. 2011;114(4):185-90. https://doi.org/10.1016/j.zool.2011.04.001.

8. Boulotte NM, Dalton SJ, Carroll AG, Harrison PL, Putnam HM, Peplow LM, Van Oppen MJH. Exploring the Symbiodinium rare biosphere provides evidence for symbiont switching in reef-building corals. ISME J. 2016;10(11): 2693-701. https://doi.org/10.1038/ismej.2016.54.

9. Brooks A of MCRL. 2018. MCR LTER: Coral Reef: Long-term Population and Community Dynamics: Fishes, ongoing since 2005

10. Brysch-Herzberg M. Ecology of yeasts in plant-bumblebee mutualism in Central Europe. FEMS Microbiol Ecol. 2004;50(2):87-100. https://doi.org/10.1 016/j.femsec.2004.06.003.

11. Burkepile DE, Hay ME. Herbivore species richness and feeding complementarity affect community structure and function on a coral reef. Proc Natl Acad Sci U S A. 2008;105(42):16201-6. https://doi.org/10.1073/pna S.0801946105.

12. Burkepile $D E$, Hay ME. Herbivore vs. nutrient control of marine primary producers: context-dependent effects. Ecology. 2006;87(12):3128-39. https:// doi.org/10.1890/0012-9658(2006)87[3128:HVNCOM]2.0.CO;2.

13. Burkepile DE, Shantz AA, Adam TC, Munsterman KS, Speare KE, Ladd MC, Rice MM, Ezzat L, Mcllroy S, Wong JCY, Baker DM, Brooks AJ, Schmitt RJ, Holbrook SJ. Nitrogen identity drives differential impacts of nutrients on coral bleaching and mortality. Ecosystems. 2020;23(4):798-811. https://doi. org/10.1007/s10021-019-00433-2.

14. Castro-Sanguino C, Sánchez JA. Dispersal of symbiodinium by the stoplight parrotfish Sparisoma viride. Biol Lett. 2012;8(2):282-6. https://doi.org/10.1 098/rsbl.2011.0836

15. Coffroth MA, Lewis CF, Santos SR, Weaver JL. Environmental populations of symbiotic dinoflagellates in the genus Symbiodinium can initiate symbioses with reef cnidarians. Curr Biol. 2006;16(23):985-7. https://doi.org/10.1016/j. cub.2006.10.049

16. Cole AJ, Pratchett MS, Jones GP. Diversity and functional importance of coral-feeding fishes on tropical coral reefs. Fish Fish. 2008;9(3):286-307. https://doi.org/10.1111/j.1467-2979.2008.00290.x

17. Correa AMS, Brandt ME, Smith TB, Thornhill DJ, Baker AC. Symbiodinium associations with diseased and healthy scleractinian corals. Coral Reefs. 2009:28(2):437-48. https://doi.org/10.1007/s00338-008-0464-6.

18. Ezzat L, Lamy T, Maher RL, Munsterman KS, Landfield KM, Schmeltzer ER, Clements CS, Thurber RLV, Burkepile DE. Parrotfish predation drives distinct microbial communities in reef-building corals. Anim Microbiome. 2020;2:1-15.

19. Foo JL, Ling H, Lee YS, Chang MW. Microbiome engineering: current applications and its future. Biotechnol J. 2017;12(3):1-11. https://doi.org/10.1 002/biot.201600099.
20. Forsman Z, Wellington GM, Fox GE, Toonen RJ. Clues to unraveling the coral species problem: distinguishing species from geographic variation in Porites across the Pacific with molecular markers and microskeletal traits. PeerJ. 2015;3:e751. https://doi.org/10.7717/peerj.751.

21. Forsman ZH, Barshis DJ, Hunter CL, Toonen RJ. Shape-shifting corals: molecular markers show morphology is evolutionarily plastic in Porites. BMC Evol Biol. 2009;9(1):45. https://doi.org/10.1186/1471-2148-9-45.

22. Fujise L, Suggett DJ, Stat M, Kahlke T, Bunce M, Gardner SG, Goyen S, Woodcock S, Ralph PJ, Seymour JR, Siboni N, Nitschke MR. Unlocking the phylogenetic diversity, primary habitats, and abundances of free-living Symbiodiniaceae on a coral reef. Mol Ecol. 2021;30(1):343-60. https://doi. org/10.1111/mec.15719.

23. Gélin P, Postaire B, Fauvelot C, Magalon H. Molecular Phylogenetics and evolution reevaluating species number, distribution and endemism of the coral genus Pocillopora Lamarck, 1816 using species delimitation methods and microsatellites. Mol Phylogenet Evol. 2017;109:430-46. https://doi.org/1 0.1016/j.ympev.2017.01.018.

24. Harmelin-Vivien ML, Bouchon-Navaro Y. Feeding diets and significance of coral feeding among Chaetodontid fishes in Moorea (French Polynesia). Coral Reefs J Int Soc Reef Stud. 1983;2(2):119-27. https://doi.org/10.1007/ BF02395282.

25. Haslun JA, Strychar KB, Buck G, Sammarco PW. Coral bleaching susceptibility is decreased following short-term (1-3 year) prior temperature exposure and evolutionary history. J Mar Biol. 2011;2011:1-13. https://doi.org/10.11 55/2011/406812.

26. Hawkins JP, Roberts CM, Gell FR, Dytham C. Effects of trap fishing on reef fish communities. Aquat Conserv Mar Freshw Ecosyst. 2007;17(2):111-32. https://doi.org/10.1002/aqc.

27. Howe-Kerr LI, Bachelot B, Wright RM, Kenkel CD, Bay LK, Correa AMS. Symbiont community diversity is more variable in corals that respond poorly to stress. Glob Chang Biol. 2020;26(4):2220-34. https://doi.org/1 $0.1111 /$ gcb. 14999 .

28. Hughes TP, Kerry J, Álvarez-Noriega M, Álvarez-Romero J, Anderson K, Baird A, Babcock R, Beger M, Bellwood D, Berkelmans R, Bridge T, Butler I, Byrne M, Cantin N, Comeau S, Connolly S, Cumming G, Dalton S, Diaz-Pulido G, Eakin CM, Figueira W, Gilmour J, Harrison H, Heron S, Hoey AS, Hobbs J-P, Hoogenboom M, Kennedy E, Kuo C-Y, Lough J, Lowe R, Liu G, Malcolm McCulloch HM, McWilliam M, Pandolfi J, Pears R, Pratchett M, Schoepf V, Simpson T, Skirving W, Sommer B, Torda G, Wachenfeld D, Willis B, Wilson S. Global warming and recurrent mass bleaching of corals. Nature. 2017; 543(7645):373-7. https://doi.org/10.1038/nature21707.

29. Hume BCC, Smith EG, Ziegler M, Warrington HJM, Burt JA, LaJeunesse TC, Wiedenmann J, Voolstra CR. SymPortal: a novel analytical framework and platform for coral algal symbiont next-generation sequencing ITS2 profiling. Mol Ecol Resour. 2019;19(4):1063-80. https://doi.org/10.1111/1 755-0998.13004

30. Hume BCC, Ziegler M, Poulain J, Pochon X, Romac S, Boissin E, de Vargas $C$, Planes S, Wincker P, Voolstra CR. An improved primer set and amplification protocol with increased specificity and sensitivity targeting the Symbiodinium ITS2 region. PeerJ. 2018;2018:1-22. https://doi.org/10.7717/ peerj.4816.

31. Jiménez RR, Sommer $S$. The amphibian microbiome: natural range of variation, pathogenic dysbiosis, and role in conservation. Biodivers Conserv. 2017;26(4):763-86. https://doi.org/10.1007/s10531-016-1272-x.

32. LaJeunesse TC, Parkinson JE, Gabrielson PW, Jeong HJ, Reimer JD, Voolstra CR, Santos SR. Systematic revision of Symbiodiniaceae highlights the antiquity and diversity of coral Endosymbionts. Curr Biol. 2018;28:2570-80.e6. https://doi.org/10.1016/j.cub.2018.07.008.

33. LaJeunesse TC, Pinzón JH. Screening intragenomic rDNA for dominant variants can provide a consistent retrieval of evolutionarily persistent ITS (rDNA) sequences. Mol Phylogenet Evol. 2007;45(1):417-22. https://doi.org/1 0.1016/.ympev.2007.06.017.

34. Lewis CL, Coffroth MA. The acquisition of exogenous, algal symbionts by an octocorat after bleaching. Science (80- ) 304:1490-1492. 2004. https://doi. org/10.1126/science.1097323.

35. Littman RA, Van Oppen MJH, Willis BL. Methods for sampling free-living Symbiodinium (zooxanthellae) and their distribution and abundance at Lizard Island (great barrier reef). J Exp Mar Bio Ecol. 2008;364(1):48-53. https://doi.org/10.1016/j.jembe.2008.06.034.

36. Martinez Arbizu P. 2020. pairwiseAdonis: pairwise multilevel comparison using Adonis. R package 0.4 . 
37. McClanahan TR, Muthiga NA, Kamukuru AT, Machano H, Kiambo RW. The effects of marine parks and fishing on coral reefs of northern Tanzania. Biol Conserv. 1999;89(2):161-82. https://doi.org/10.1016/S0006-3207(98)00123-2.

38. McFall-Ngai M, Hadfield MG, Bosch TCG, Carey HV, Domazet-Lošo T, Douglas AE, Dubilier N, Eberl G, Fukami T, Gilbert SF, Hentschel U, King N, Kjelleberg S, Knoll AH, Kremer N, Mazmanian SK, Metcalf JL, Nealson K, Pierce NE, Rawls JF, Reid A, Ruby EG, Rumpho M, Sanders JG, Tautz D, Wernegreen JJ. Animals in a bacterial world, a new imperative for the life sciences. Proc Natl Acad Sci. 2013;110(9):3229-36. https://doi.org/10.1073/ pnas.1218525110.

39. Mcllroy SE, Coffroth MA. Coral ontogeny affects early symbiont acquisition in laboratory-reared recruits. Coral Reefs. 2017;36(3):927-32. https://doi.org/1 0.1007/s00338-017-1584-7.

40. Mcllroy SE, Gillette P, Cunning R, Klueter A, Capo T, Baker AC, Coffroth MA. The effects of Symbiodinium (Pyrrhophyta) identity on growth, survivorship, and thermal tolerance of newly settled coral recruits. J Phycol. 2016;52(6): 1114-24. https://doi.org/10.1111/jpy.12471.

41. Moran NA, Sloan DB. The Hologenome concept: helpful or hollow? PLoS Biol. 2015;13(12):1-10. https://doi.org/10.1371/journal.pbio.1002311.

42. Morgans CA, Hung JY, Bourne DG, Quigley KM. Symbiodiniaceae probiotics for use in bleaching recovery. Restor Ecol. 2020;28(2):282-8. https://doi.org/1 $0.1111 /$ rec. 13069 .

43. Muller PG. Dispersal of zooxanthellae on coral reefs by predators on cnidarians. Biol Bull. 1984;167:159-67.

44. Muscatine L, Falkowski PG, Porter JW, Dubinsky Z. Fate of photosynthetic fixed carbon in light- and shade-adapted colonies of the symbiotic coral Stylophora pistillata. Proc R Soc London Biol. 1984;222:181-202.

45. Nitschke MR, Davy SK, Ward S. Horizontal transmission of Symbiodinium cells between adult and juvenile corals is aided by benthic sediment. Coral Reefs. 2016;35(1):335-44. https://doi.org/10.1007/s00338-015-1349-0.

46. Oksanen J, Blanchet G, Friendly M, Kindt R, Legendre P, McGlinn D, R. PM, O'Hara RB, Simpson GL, Solymos P, Stevens MHH, Szoecs E, Wagner H. 2019. vegan: Community Ecology Package. R package version 2.4-6. R Packag version 25-6. doi:https://CRAN.R-project.org/package=vegan

47. Peixoto R, Rosado P, Leite D, Rosado AS, Bourne D. Beneficial microorganisms for corals (BMC): proposed mechanisms for coral health and resilience. Front Microbiol. 2017:8:1-16. https://doi.org/10.3389/fmicb.2 017.00341.

48. Petton B, Bruto M, James A, Labreuche $Y$, Alunno-Bruscia M, Le Roux F. Crassostrea gigas mortality in France: the usual suspect, a herpes virus, may not be the killer in this polymicrobial opportunistic disease. Front Microbiol. 2015;6:686. https://doi.org/10.3389/fmicb.2015.00686.

49. Poland DM, Coffroth MA. Trans-generational specificity within a cnidarianalgal symbiosis. Coral Reefs. 2017;36(1):119-29. https://doi.org/10.1007/s0033 8-016-1514-0.

50. Pratchett MS. Chapter 6: feeding preferences and dietary specialisation among obligate coral-feeding butterflyfishes. In: Pratchett MS, editor. Biology of butterflyfishes. Boca Raton: CRC press; 2014. p. 140-79.

51. Pratchett MS, Wilson SK, Baird AH. Declines in the abundance of Chaetodon butterflyfishes following extensive coral depletion. J Fish Biol. 2006;69(5): 1269-80. https://doi.org/10.1111/j.1095-8649.2006.01161.x.

52. Putnam HM, Stat M, Pochon $X$, Gates RD. Endosymbiotic flexibility associates with environmental sensitivity in scleractinian corals. Proc R Soc B Biol Sci. 2012;279(1746):4352-61. https://doi.org/10.1098/rspb.2012.1454.

53. Rebollar EA, Simonetti SJ, Shoemaker WR, Harris RN. Direct and indirect horizontal transmission of the antifungal probiotic bacterium Janthinobacterium lividum on green frog (Lithobates clamitans) tadpoles. Appl Environ Microbiol. 2016;82(8):2457-66. https://doi.org/10.1128/AEM. 04147-15.

54. Reshef L, Koren O, Loya Y, Zilber-Rosenberg I, Rosenberg E. The coral probiotic hypothesis. Environ Microbiol. 2006;8(12):2068-73. https://doi. org/10.1111/j.1462-2920.2006.01148.x.

55. Rosado PM, Leite DCA, Duarte GAS, Chaloub RM, Jospin G, Nunes da Rocha U, Saraiva PJ, Dini-Andreote F, Eisen JA, Bourne DG, Peixoto RS. Marine probiotics: increasing coral resistance to bleaching through microbiome manipulation. ISME J. 2019;13(4):921-36. https://doi.org/10.1038/s41396-0180323-6.

56. Rosenberg E, Koren O, Reshef L, Efrony R, Zilber-Rosenberg I. The role of microorganisms in coral health, disease and evolution. Nat Rev Microbiol. 2007:5(5):355-62. https://doi.org/10.1038/nrmicro1635.
57. Rotjan RD, Lewis SM. Impact of coral predators on tropical reefs. Mar Ecol Prog Ser. 2008;367:73-91. https://doi.org/10.3354/meps07531.

58. Rouzé H, Lecellier G, Pochon X, Torda G, Berteaux-Lecellier V. Unique quantitative Symbiodiniaceae signature of coral colonies revealed through spatio-temporal survey in Moorea. Sci Rep. 2019;9(1):1-11. https://doi.org/1 0.1038/s41598-019-44017-5.

59. Smriga S, Sandin SA, Azam F. Abundance, diversity, and activity of microbial assemblages associated with coral reef fish guts and feces. FEMS Microbiol Ecol. 2010;73:31-42. https://doi.org/10.1111/j.1574-6941.2010.00879.x.

60. Strychar K, Coates M. Loss of Symbiodinium from bleached Australian scleractinian corals (Acropora hyacinthus, Favites complanata and Porites solida). Mar Freshw Res. 2004;55(2):135-44. https://doi.org/10.1071/MF03080.

61. Suzuki G, Yamashita H, Kai S, Hayashibara T, Suzuki K, lehisa Y, Okada W, Ando W, Komori T. Early uptake of specific symbionts enhances the postsettlement survival of Acropora corals. Mar Ecol Prog Ser. 2013;494:149-58. https://doi.org/10.3354/meps10548.

62. Team RC. 2019. R: a language and environment for statistical computing. $R$ Foundation for statistical computing. R Foundation for statistical computing, Vienna, Austria. Doi: URL https://www.R-project.org/

63. Umeki M, Yamashita H, Suzuki G, Sato T, Ohara S, Koike K. Fecal pellets of giant clams as a route for transporting Symbiodiniaceae to corals. PLoS One. 2020;15(12):1-15. https://doi.org/10.1371/journal.pone.0243087.

64. Vašutová M, Mleczko P, López-García A, Maček I, Boros G, Ševčík J, Fujii S, Hackenberger D, Tuf IH, Hornung E, Páll-Gergely B, Kjøller R. Taxi drivers: the role of animals in transporting mycorrhizal fungi. Mycorrhiza. 2019;29(5): 413-34. https://doi.org/10.1007/s00572-019-00906-1.

65. Viviani J, Lecchini D, Moritz C, Siu G, Galzin R, Viriot L. Synchrony patterns reveal different degrees of trophic guild vulnerability after disturbances in a coral reef fish community. Divers Distrib. 2019:1210-21. https://doi.org/1 $0.1111 /$ ddi.12931.

66. Weis VM. Cellular mechanisms of cnidarian bleaching: stress causes the collapse of symbiosis. J Exp Biol. 2008;211(19):3059-66. https://doi.org/1 0.1242/jeb.009597.

67. Wilkinson C. Status of coral reefs of the world: 2008 global coral reef monitoring network and reef and rainforest research center. Australia: Townsville; 2008.

68. Zhang $Y$, Li Q, Hui N, Fei M, Hu Z, Sun S. Effect of formaldehyde treatment on the recovery of cell-free fetal DNA from maternal plasma at different processing times. Clin Chim Acta. 2008;397(1-2):60-4. https://doi.org/10.101 6/j.cca.2008.07.017.

\section{Publisher's Note}

Springer Nature remains neutral with regard to jurisdictional claims in published maps and institutional affiliations.

\section{Ready to submit your research? Choose BMC and benefit from:}

- fast, convenient online submission

- thorough peer review by experienced researchers in your field

- rapid publication on acceptance

- support for research data, including large and complex data types

- gold Open Access which fosters wider collaboration and increased citations

- maximum visibility for your research: over 100M website views per year

At $\mathrm{BMC}$, research is always in progress.

Learn more biomedcentral.com/submissions 